\title{
Physical fitness, nutritional habits and daily locomotive action of 12-year-old children with different body mass index
}

\author{
Spiridon Kamtsios (MSc) \\ Physical Education Teacher, Ioannina, Greece
}

\begin{abstract}
Objective. The purpose of this study was to examine the differences in physical fitness, daily nutritional habits and locomotive behaviour among pupils with varying body mass index (BMI) in the 5th and 6th grades of primary school.

Design. The sample consisted of 480 pupils (229 boys and 251 girls), who participated in specific Eurofit tests and completed questionnaires probing their physical activity and nutritional habits. They were divided according to their BMI into normal, overweight or obese children.
\end{abstract}

Main outcome measures. $18 \%$ and $8 \%$ of the pupils were categorised as overweight and obese, respectively.

Results. From the data analysis (two-way ANOVA), with BMI and gender as independent variables, it was found that the obese and overweight pupils had lower performance in long jump, in 30-m speed and in 20-m shuttle run. They adopted sedentary daily habits, such as many hours of TV watching and unhealthly nutritional habits.

Conclusions. The results of this study support the need for intervention at school through physical education and health education lessons, to inform pupils about the health risks associated with limited physical activity and unhealthy nutritional habits. Another goal should be to motivate and create behaviours that are conducive to better lifestyle habits.

\section{CORRESPONDENCE:}

Spiridon Kamtsios

Euergeton 42, TK 45333

loannina

Greece

Tel: +06 4-633-8714

E-mail: spiroskam@sch.gr

\section{Introduction}

Physical activity is important for the health status of any age group, and especially for young people. Studies show that children and adolescents who participate in regular physical activity can gain psychological health and skeletal health benefits. ${ }^{3}$ Regular physical activity is associated with enhanced health and reduced risk of all-cause mortality, it improves aerobic capacity, muscular strength, body agility, co-ordination and metabolic functioning, exemplified by improvements in bone density, lipid profiles, insulin levels and immune function. ${ }^{28}$ Those who are physically active have a reduced risk of developing cardiovascular disease and ischaemic stroke, ${ }^{30}$ non-insulin-dependent (type 2) diabetes, ${ }^{12}$ colon cancers, ${ }^{2}$ and osteoporosis. ${ }^{25}$ Physical activity is also consistently related to higher levels of self-esteem and lower levels of anxiety and stress. ${ }^{27}$

However, while the positive effects of regular physical activity are well established in children and adolescents, there is evidence that young people in many developed nations do not participate in regular physical activity of the type and intensity associated with health. As a result, the prevalence of childhood obesity is increasing worldwide. ${ }^{19}$ Since obesity is associated with increased morbidity and mortality, the World Health Organization has compared the marked increase to a global epidemic disease. $^{31}$

The overweight and obese child is not physically active, has a sedentary way of life and no interest in exercise. Psychological consequences of obesity may have a powerful effect on the self-image and social standing of the overweight and obese child during critical phases of emotional development. Studies evaluating the influence of obesity on mental health portray a disturbing picture of depression, low self-esteem, poor body image, and social isolation. The failure to achieve success with dieting and other therapeutic interventions may potentiate these negative feelings, and the inability to participate in physical activity and discrimination by peers and adults are further contributing influences. ${ }^{24}$

Many studies have shown that obese children and adolescents are physically less active and less fit than their non-obese peers. ${ }^{9}$ Physical fitness is generally considered to be 'the ability to perform daily tasks without fatigue'. Physical fitness includes several components: cardiorespiratory fitness, muscular endurance, muscular strength, flexibility, co-ordination and speed. ${ }^{6}$ 
Increasing physical activity is one of the key elements in the treatment of childhood obesity. ${ }^{23}$ However, motivating obese subjects to adhere to an activity programme is a major challenge. ${ }^{26}$ To improve adherence one must develop an exercise programme that is manageable for obese children and adolescents. ${ }^{23}$ Interventions that are not tailored to the fitness levels of obese participants may discourage future participation in physical activity. The ability to develop physical activity programmes suited to obese participants requires further investigation of different components of physical fitness in this population.

The purpose of this study was to examine the differences in physical fitness, daily nutritional habits and locomotive behaviour among pupils with varying body mass index (BMI) in the 5th and 6 th grades of primary school. The hypothesis of the research is that overweight and obese children will have differences in fitness levels and they will adopt a sedentary lifestyle.

\section{Material and methods}

\section{Participants and study design}

The study included 480 children (229 boys and 251 girls) aged 11 - 12 years (mean $11.62 \pm 0.60$ years), attending the 5 th and 6th grade classes of primary schools which were selected with stratified sampling in suburban and urban areas of west-northwest Greece. The nature and purpose of the study were explained to parents before consent was obtained, and participation was on a voluntary basis. The measurements and the tests that the children underwent were carried out during the first two school hours. The data collected included anthropometric measurements as well as motor- and health-related fitness parameters.

\section{Anthropometric measurements}

Age (accurate to 1 month) was recorded. Height was measured with a stadiometer to the nearest $0.5 \mathrm{~cm}$. Body mass was measured on a balance-beam scale accurate to $0.1 \mathrm{~kg}$. The students were barefoot, wearing light clothing to decrease the additional weight. Body mass index (BMI) was calculated by dividing weight by height squared $\left(\mathrm{kg} \cdot \mathrm{m}^{-2}\right)^{7}$

\section{Physical fitness measurements}

The physical fitness of the children was evaluated with the Eurofit test battery, ${ }^{8}$ which is designed for the assessment of healthrelated fitness in children and adults. Eurofit for children is designed to be practical and applicable under conditions available in ordinary communities. The children wore athletic shoes and athletic clothes and underwent the following tests that measure different components of fitness.

- Sit and reach (SAR): Reaching as far as possible from a sitting position. This test measures the flexibility of posterior muscles.

- Standing long jump with feet together (SLJ): The maximum horizontal distance attained was measured. This test evaluates the explosive strength of the legs.

- Sit-ups (SUP): The maximum number of sit-ups achieved in 30 seconds was recorded. This test measures the trunk strength (muscular endurance).
- Overhand throw: The test measures the strength of the upper body limbs.

- 30-meter sprint (from standing position): This test measures speed.

- 20-meter multistage aerobic shuttle run test (MAT): This test evaluates the maximum aerobic capacity based on an indirect-incremental-maximum field test involving a 20-meter shuttle run, using the formula proposed by Léger et al. to calculate the maximal oxygen consumption $\left(\mathrm{VO}_{2 \mathrm{max}}\right)^{16}$

\section{Students' daily locomotive and nutritional habits}

Responders were asked how often and how many times each week they 'participated in sports, swimming or other physical activities, excluding mandatory physical education classes in school'. They were also asked about their nutritional habits during the last week and about their sedentary habits ('How many hours do you watch TV on a week day and on the weekend?').

\section{Statistical analyses}

Descriptive statistics were performed for all parameters. A twoway ANOVA was used to examine differences in group means. A Sidak post hoc test was used to identify differences among gender and BMI categories (Sidak was used to compare variables from different data collections) and effect sizes $\left(\eta^{2}-\right.$ i.e. proportion of the total variance that is attributed to an effect) were calculated to assess the significance of the differences in fitness performance among BMI categories. Comparisons were considered significant at a $p$-value of 0.05 or less. Chi-square tests were used to detect differences between normal, overweight and obese children in their daily locomotive and nutritional habits. SPSS version 11.0 software was used for all statistical calculations.

\section{Results}

When the entire sample including both genders was analysed, $74 \%$ of the participants had a normal BMI, $18 \%$ were overweight and $8 \%$ were characterised as obese.

The differences in the fitness parameters among BMI categories by gender are presented in Table I. Two-way ANOVA results revealed a significant effect of $\mathrm{BMI}$ and gender in the multistage aerobic shuttle run test $\left(p=0.001, \eta^{2}=0.028\right)$, and in flexibility $\left(p=0.002, \eta^{2}=0.025\right)$. Specifically, normal boys performed better than their obese counterparts in standing long jump $\left(p=0.000, \eta^{2}=0.111\right)$, in sit-ups $\left(p=0.010, \eta^{2}=0.019\right)$, in sprint $\left(p=0.000, \eta^{2}=0.237\right)$, and in the multistage aerobic shuttle run test $\left(p=0.001, \eta^{2}=0.08\right)$. In addition, overweight boys demonstrated better performance than obese boys in the standing long jump, the overhand throw, sprint and in the multistage aerobic shuttle run test ( $p$-values between 0.004 and 0.001). Normal-weight girls performed better in the sprint than their overweight and obese counterparts $(p=0.001)$. In the comparison of physical fitness tests between genders within the BMI categories, boys obtained better results than girls for all tests except flexibility.

Tables II and III present the results of chi-square tests examining the differences between some discernible variables related to the daily athletic, locomotive and nutritional habits. Significant differences were found between the three cohorts, with the obese children displaying a higher percentage in all categories. 
TABLE I. Mean (SD) differences in the fitness parameters among BMI categories by gender

\begin{tabular}{|c|c|c|c|c|c|c|c|c|c|}
\hline & \multicolumn{3}{|c|}{ Boys $(n=229)(47.7 \%)$} & \multicolumn{3}{|c|}{ Girls ( $n=251)(52.3 \%)$} & \multirow[b]{2}{*}{$\mathrm{F}_{\mathrm{BMI}}$} & \multirow[b]{2}{*}{$F_{\text {gender }}$} & \multirow[b]{2}{*}{$F_{\text {bmi xgender }}$} \\
\hline & $\begin{array}{l}\text { Normal } \\
\mathrm{N}=162\end{array}$ & $\begin{array}{l}\text { Overweight } \\
\mathrm{N}=46\end{array}$ & $\begin{array}{l}\text { Obese } \\
\mathrm{N}=21\end{array}$ & $\begin{array}{l}\text { Normal } \\
\mathrm{N}=194\end{array}$ & $\begin{array}{l}\text { Overweight } \\
\mathrm{N}=38\end{array}$ & $\begin{array}{l}\text { Obese } \\
\mathrm{N}=19\end{array}$ & & & \\
\hline \multicolumn{10}{|l|}{ Motor fitness tests } \\
\hline $\mathrm{SAR}(\mathrm{cm})$ & $14.11,2 \pm 6.1$ & $11.01,3 \pm 9.3$ & $13.74 \pm 7.3$ & $19.12 \pm 6.1$ & $21.43 \pm 4.8$ & $18.14 \pm 8.3$ & .25 & $57.8^{*}$ & $6.1^{*}$ \\
\hline $\mathrm{SLJ}(\mathrm{cm})$ & $1.41,2 \pm 0.17$ & $1.31,3 \pm 0.2$ & $1.21 \pm 0.2$ & $1.91,2 \pm 0.14$ & $1.21,3 \pm 0.1$ & $1.1 \pm 0.1$ & $29.6^{*}$ & $13.4^{*}$ & .08 \\
\hline SUP (reps in 30s) & $18.11 \pm 4.7$ & $19.3 \pm 4.1$ & $14.81 \pm 4.3$ & $17.8 \pm 4.5$ & $18.1 \pm 5.1$ & $16.5 \pm 5.5$ & $4.61^{*}$ & 2.6 & 2.2 \\
\hline OTHR (m) & $4.92 \pm 1.5$ & $5.41 \pm 1.7$ & $4.41 \pm 2.9$ & $4.32 \pm 1.3$ & $4.9 \pm 1.5$ & $3.9 \pm 1.9$ & $5.8^{*}$ & $6.4^{*}$ & .16 \\
\hline SPR (s) & $5.91 \pm 0.4$ & $6.21,3 \pm 0.5$ & $6.91 \pm 0.2$ & $6.21,2 \pm 0.46$ & $6.51,3 \pm 0.4$ & $7.11 \pm 0.1$ & $73.6^{*}$ & $17.2^{*}$ & .14 \\
\hline MAT $\left(\mathrm{ml} \mathrm{kg}^{-1} \min ^{-1}\right)$ & $29.81,2 \pm 9.4$ & $23.91 \pm 5.0$ & $24.1 \pm 4.8$ & $24.72 \pm 4.3$ & $24.6 \pm 4.1$ & $21.7 \pm 1.5$ & $13.6^{\dagger}$ & $6.4^{\dagger}$ & $6.8^{\dagger}$ \\
\hline $\begin{array}{l}\text { Values are mean } \pm \text { SD } \\
\text { SAR = sit and reach; SLJ } \\
1=\text { Differences between nc } \\
2=\text { Gender differences bet } \\
3=\text { Gender differences bet } \\
4=\text { Gender differences bet } \\
\text { "Significantly different at } t \\
{ }^{*} \text { Significantly different at }\end{array}$ & $\begin{array}{l}\text { standing long jum } \\
\text { mal, overweight an } \\
\text { een normal childre } \\
\text { een overweight chi } \\
\text { een obese children } \\
0.05 \text { level } \\
\text { e } 0.001 \text { level }\end{array}$ & $\begin{array}{l}\text { SUP = sit ups; OT } \\
\text { obese } \\
\text { ren }\end{array}$ & $\mathrm{R}=$ overhand thro & $\mathrm{R}=$ sprint; $\mathrm{MAT}=$ & multistage aerobic & huttle run test & & & \\
\hline
\end{tabular}

TABLE II. Results of chi-square test concerning daily nutritional habits

\begin{tabular}{lll}
\hline Nutritional habits & Chi-square test & \\
\hline Salad & $\chi^{2}(2)=0.8$ & $p=0.669$ \\
Fruits & $\chi^{2}(2)=30.2^{*}$ & $p=0.000$ \\
Cereals & $\chi^{2}(2)=2.0$ & $p=0.368$ \\
Milk & $\chi^{2}(2)=2.1$ & $p=0.353$ \\
Hamburger & $\chi^{2}(2)=55.7^{*}$ & $p=0.000$ \\
Coca-cola & $\chi^{2}(2)=38.2^{*}$ & $p=0.000$ \\
* Values significantly different $(p<0.05)$. &
\end{tabular}

TABLE III. Results of chi-square test concerning daily athletic and locomotive habits

\begin{tabular}{lll}
\hline \multicolumn{3}{l}{ Chi-square test } \\
\hline School team member & $\chi^{2}(2)=23.9^{*}$ & $p=0.000$ \\
Participation as an athlete in a club & $\chi^{2}(2)=10.9^{*}$ & $p=0.004$ \\
Exercise during leisure time with friends & $\chi^{2}(2)=3.4$ & $p=0.186$ \\
TV daily & $\chi^{2}(2)=14.1^{*}$ & $p=0.028$ \\
Daily PC usage & $\chi^{2}(2)=2.2$ & $p=0.703$ \\
*Values significantly different $(p<0.05)$. & & \\
\end{tabular}

\section{Discussion}

The principal findings in the present study were that obese and overweight pupils had lower performance in specific physical fitness tests and they adopted sedentary daily habits, such as many hours of TV watching and unhealthy nutritional habits. Our results support the findings of previous studies in Greece ${ }^{20,10,18}$ and in other countries ${ }^{4,29}$ that the prevalence of overweight and obesity in 10 - 12-year-olds was approximately $30 \%$.

The results showed that overweight and obese students had inferior performances in all tests requiring propulsion or lifting of the body mass (standing-broad jump, sit-ups, and endurance shuttle run). These poorer performances in obese individuals are probably due to the fact that their excess body fat is an extra load to be moved during weight-bearing tasks. Another explanation could be that obese children and adolescents avoid weightbearing activities because of the greater energy cost compared with normal-weight children. In this case, the poorer performance could also be a consequence of a lack of experience in weightbearing tasks. Because obese young boys and girls are limited in their ability to perform weight-bearing activities, such activities should be limited at the start of an intervention programme. Activities that are not tailored to the capabilities of bigger children may discourage continued participation by obese individuals. ${ }^{9}$ Once levels of fatness have decreased and/or fitness levels have improved, weight-bearing tasks may be much less exhausting and should be progressively included in the programme. ${ }^{9}$

No relationship was found between obesity and flexibility, something that was mentioned in previous studies. ${ }^{21}$ Useful non-weight-bearing alternatives such as cycling, swimming or other aquatic activities should be the focus in the early stages of a programme and then continued as an appropriate means of balancing various types of activity. ${ }^{9,23}$

The second research question was related to differences in the children's nutritional habits and in their daily locomotive habits. Results showed that overweight and obese children watched more hours of TV in the weekday and the weekends. Other studies have also found negative relationships between television viewing times and obesity. ${ }^{14}$ Television watching replaces more vigorous activities. There is a positive correlation between time spent watching television and being overweight or obese in populations of different ages. Prevalence of obesity has increased as well as the number of hours that TV networks dedicate to children. ${ }^{13}$ In addition, children are exposed to many unhealthy stimulations in terms of food intake when watching television. Over the last few years, the number of television food commercials targeting children have increased, especially junk food. The current use of food in movies, shows and cartoons may lead to a misconception of the notion of healthy nutrition and stimulate an excessive intake of poor nutritional food. ${ }^{5}$

Another finding of this study was that overweight and obese children were less likely to join an organised athletic club. Sports clubs may be too competition oriented and therefore not appropriate for the less-fit children and adolescents, which 
would include the obese. Given the commonly low levels of sports participation by the obese, the encouragement of sports participation from an early age may be important in the prevention and treatment of overweight. ${ }^{9}$

No relationship was found between video game/computer use and the BMI among children. This may be because primary school children in this study spent relatively little time in these activities, because these activities are less sedentary than television viewing, or due to other factors which were not explored in this study (i.e. no food advertising, hands not free for eating during video game/computer use). There is not much research to which we could compare our findings. ${ }^{29}$

The phenomenon of fatness and all its contributory factors in childhood and adolescence is an important problem - it can become one of the most common diseases and can turn into a world-wide epidemic. Important causes for this are lack of physical activity and sedentary lifestyle. A goal for managing the overweight and obese children is to urge them to become physically active, in an attempt to influence them to adopt these habits as adults. In addition to the physical effects, this will also have psychological and social benefits. ${ }^{22}$ Exercise programmes include lifestyle changes, e.g. walking instead of taking a bus, using stairs instead of lifts, as well as exercise in a planned and structured manner, e.g. participating in sport or gymnastic groups. Another aspect is that inactive periods (sedentary activities, TV and video viewing, etc.) during the day should be exchanged as much as possible for active behaviour. Recent studies suggest that decreasing sedentary activity is very effective in promoting weight loss. ${ }^{32}$ Strategies to increase physical activity are therefore key elements in the treatment of childhood obesity, along with changes in eating behaviour. ${ }^{9}$

The current environmental experience of young children includes few opportunities for physical activity. To prevent obesity and later metabolic disease, all sectors of society must work together to support strategies to change public opinion and behaviour across the lifespan. Schools should be primary targets for efforts to educate children on the reduction of TV time, computer games and unhealthy snacks. Schools should provide daily physical education and frequent periods of unstructured play in young children. School interventions through physical education lessons must be provided to inform children about health risks related to inactivity and unhealthy nutritional habits. Another goal should be to motivate and create behaviours that are conducive to better lifestyle habits.

\section{REFERENCES}

1. Brewer J, Ramsbottom R, Williams C. Multistage Fitness Test. A Progressive Shuttle Run Test for the Prediction of Maximum Oxygen Uptake. Leeds, UK: National Coaching Foundation, 1988.

2. Brownson RC, Chang JC, Davis JR, Smith CA. Physical activity on the job and cancer in Missouri. Am J Publ Health 1991; 81: 639-42.

3. Calfas CJ, Taylor WC. Effects of physical activity on psychological variables of children. Ped Exerc Science 1994; 6: 406-23.

4. Canning P, Courage M, Frizzell L. Prevalence of overweight and obesity in a provincial population of Canadian preschool children. J Canad Med Assoc 2004; 171(3): 101-7.

5. Caroli M, Argentieri L, Cardone M, Mase A. Role of television in childhood obesity prevention. Intern J Obes 2004; 28: 104-8.

6. Caspersen CJ, Powell KE, Christenson GM. Physical activity, exercise and physical fitness: definitions and distinctions for health-related research. Publ Health Res 1985; 100:126-31.

7. Cole TJ, Bellizzi C, Flegal KM, Dietz WH. Establishing a standard definition for child overweight and obesity worldwide: international survey. BMJ 2000; 320: 1240-53.
8. Committee of Experts on Sports Research. European Test of Physical Fitness (EUROFIT). Rome: Edigraf Editoriale Grafica, 1988.

9. Deforche B, Lefevre J, Bourdeaudhuij I, Hills A, Duquet W, Bouckaert J. Physical fitness and physical activity in obese and non obese Flemish youth. Obes Res 2003; 11: 434-41.

10. Digelidis N, Kamtsios S, Theodorakis Y. Physical activity levels, exercise attitudes, self-perceptions, nutritional behaviors and BMI type of 12-years children. Inquiries Sport \& Phys Educ 2007; 5(1): 27-40.

11. Frontini MG, Bao W, Elkasabany A, Srinivasan SR, Berenson G. Comparison of weight-for-height indices as a measure of adiposity and cardiovascular risk from childhood to young adulthood: the Bogalusa heart study. $J$ Clin Epidem 2001; 54: 817-22.

12. Fulton-Kehoe D, Hamman RF, Baxter J, Marshall J. A case-control study of physical activity and non-insulin dependent diabetes mellitus (NIDDM). The San Luis Valley Diabetes Study. Ann Epidem 2001; 11: 320-27.

13. Hardus PM, Vuuren C, Crawford D, Worsley A. Public perceptions of the causes and prevention of obesity among primary school children. Intern $J$ Obes 2003; 27: 1465-71.

14. Janssen I, Katzmarzyk P, Boyce N. Comparison of overweight and obesity prevalence in school aged youth from 34 countries and their relationships with physical activity and dietary patterns. Obes Rev 2005; 6: 123-32.

15. Katzmarzyk PT, Tremblay A, Perusse L, Despres J, Bouchard C. The utility of the international child and adolescent overweight guidelines for predicting coronary heart disease risk factors. J Clin Epidemiol 2003; 56: 45662

16. Léger LA, Mercier D, Gaboury C, Lambert J. The multistage 20-m shuttle run test for aerobic fitness. J Sports Sci 1988; 6(2): 93-101.

17. Lindsay RS, Hanson RL, Roumain J, Ravussin E, Knowler WC, Tataranni PA. Body mass index as a measure of adiposity in children and adolescents: relationship to adiposity by dual energy $x$-ray absorptiometry and to cardiovascular risk factors. J Clin Endocrinol Metab 2001; 86: 4061-67.

18. Magkos F, Manios $Y$, Christakis G, Kafatos AG. Secular trends in cardiovascular risk factors among school-aged boys from Crete, Greece, 19822002. Europ J Clin Nutrit 2005; 59: 1-7.

19. Marild S, Bondestam M, Bergstrom R, Ehnberg S, Hallsing A, AlbertssonWikland K. Prevalence trends of obesity and overweight among 10-yearold children in Western Sweden and relationships with parental body mass index. Acta Pediatr 2004; 93: 1588-95.

20. Mamalakis G, Kafatos A, Manios Y, Anagnostopoulou T. Apostolaki I. Obesity indices in a cohort of primary school children in Crete: a six-year prospective study. Int J Obesity 2000; 24: 765-71.

21. Minck MR, Ruiter LM, Van Mechelen W, Kemper HC, Twisk JW. Physical fitness, body fatness, and physical activity: the Amsterdam Growth Study. J Hum Biol 2000; 12: 593-9.

22. Mota J, Santos P, Guerra S, Ribeiro J, Duarte J. Differences of daily physical activity levels of children according to body mass index. Pediatr Exer Scie 2000; 14: 442-52.

23. Parizková J, Hills A. Childhood Obesity: Prevention and Management. Boca Raton: CRC Press, 2001.

24. Rowland T. Exercise and children's health. In: Cheung W, Richmond J, eds. Obesity and Physical Activity. Champaign, IL: Human Kinetics Publishers, 1990: 129-159.

25. Rubin K, Schirduan V, Gendreau P, Sarfarazi M, Mendola R, Dalsky G. Predictors of axial and peripheral bone mineral density in healthy children and adolescents, with special attention to the role of puberty. $J$ Pediatr 1993; 123: 863-70.

26. Sothern MS, Hunter S, Suskind RM, Brown R, Udall JN, Blecker U. Motivating the obese child to move: the role of structured exercise in pediatric weight management. South Med J 1999; 92: 577-83.

27. Theodorakis $Y$, Natsis P, Papaioannou A, Goudas M. Correlation between exercise and other health related behaviors in Greek students. Int J Phys Educ 2002; 39: 30-4.

28. US Department of Health and Human Services. Physical Activity and Health: A Report of the Surgeon General. Atlanta, GA: US Centers for Disease Control and Prevention, 1996.

29. Wake M, Hesketh K, Waters E. Television, computer use and body mass index in Australian primary school children. J Pediatr Child Health 2003; 38: $130-34$.

30. Wannamethee SG, Shaper AG. Physical activity in the prevention of cardiovascular disease: an epidemiological perspective. Sports Med 2001; 31: 101-14

31. World Health Organization. Obesity: Preventing and Managing the Global Epidemic. Report of a WHO consultation. World Health Organization, Technical Report Series 894. Geneva: WHO, 2000.

32. Zwiauer K. Prevention and treatment of overweight and obesity in children and adolescents. J Pediatr 2000; 159: 56-68. 